\title{
Metode Cepat Identifikasi Flavonoid dari Daun Ocimum sanctum L. (Selasih)
}

\author{
Diah Dhianawaty, Ramdan Panigoro, Samsudin Surialaga, Pricilla Purushothman \\ Departemen Biokimia Fakultas Kedokteran Universitas Padjadjaran Bandung
}

\begin{abstract}
Abstrak
Manfaat suatu tumbuhan sebagai obat herbal diperoleh dari kandungan kimianya, misalnya flavonoid. Flavonoid bermanfaat untuk kesehatan tubuh manusia. Oleh karena itu, kandungan flavonoid dapat dijadikan sebagai acuan manfaat suatu tanaman dan dibutuhkan metode identifikasi flavonoid yang cepat. Tujuan penelitian untuk memperoleh metode cepat kandungan flavonoid dalam Ocimum sanctum. Telah dilakukan penelitian ekstraksi, isolasi, dan identifikasi flavonoid daun Ocimum sanctum di laboratorium Kimia Medik Fakultas Kedokteran Universitas Padjadjaran pada tahun 2005. Flavonoid diekstraksi sinambung dengan etanol 95\%, diisolasi dengan kromatografi kertas/lapis tipis selulose dan asam asetat $\%$, kemudian dilanjutkan dengan pengembang: n-butanol-asam asetat-air, kloroform-asam asetat-air, forestall, asam asetat 5\%, 15\%, 35\%, dan 50\%. Flavonoid diidentifikasi dengan pereaksi geser dan sinar ultraviolet. Hasil isolasi dengan asam asetat $2 \%$ dan $35 \%$ berturutturut memberikan dua bercak flavonoid, sebagai flavon, FOAc-1 mempunyai $\mathrm{Rf}=0,69$ dan FOAc- 2 mempunyai $\mathrm{Rf}=0,57$. Pengembang lainnya memberikan satu bercak flavonoid. Simpulan, isolasi dengan asam asetat $2 \%$ dan $35 \%$ berturut-turut serta identifikasi dengan pereaksi geser dan sinar ultraviolet merupakan metode yang cepat untuk identifikasi kandungan flavonoid dalam Ocimum sanctum. [MKB. 2012;44(1):32-7].
\end{abstract}

Kata kunci: Flavonoid, identifikasi flavonoid, Ocimum sanctum

\section{Rapid Identification Method of Flavonoid from Ocimum sanctum L. (Selasih) Leaves}

\begin{abstract}
A plant's effectiveness as a herbal drug comes from its chemical content such as flavonoids. Flavonoids are useful for human body health. Therefore flavonoids content can be used as a marker from the usefulness of a plant, and rapid identification method of flavonoid is needed. The objective of the research was to get a rapid method of flavonoid content identification from Ocimum sanctum. The extraction, isolation and identification of flavonoids from Ocimum sanctum leaves has been done at Medical Chemistry laboratory Faculty of Medicine Universitas Padjadjaran in 2005. Flavonoids were extracted continually by $95 \%$ ethanol, were isolated with paper chromatography/cellulose TLC and $2 \%$ acetic acid, then continued with elucidation reagents: n-butanol-acetic acid-water, chloroform-acetic acid-water, forestall, 5\%,15\%,35\% and 50\% acetic acids. Flavonoids were identified with diagnostic reagents and ultraviolet light. Isolation with $2 \%$ and $35 \%$ acetic acids respectively gave two spots of flavonoids as flavon, FOAc- 1 had $\mathrm{Rf}=0.69$ and FOAc- 2 had $\mathrm{Rf}=0.57$. The other elucidation reagents gave one spot of flavonoid. In conclusion, isolation with $2 \%$ and $35 \%$ acetic acids respectively and identification with diagnostic reagent and ultraviolet light is a rapid method for identification of flavonoids content in Ocimum sanctum. [MKB. 2012;44(1):32-7].
\end{abstract}

Key words: Flavonoid, identification of flavonoid, Ocimum sanctum Korespondensi: Diah Dhianawaty D., dr., M.Si, Departemen Biokimia Fakultas Kedokteran Universitas Padjadjaran
Bandung, jalan Raya Bandung Sumedang km 21, telepon (022) 7794560, mobile 08122366990,

e-mail diahdhianawaty@yahoo.com 


\section{Pendahuluan}

Manfaat suatu tumbuhan sebagai obat herbal, diperoleh dari kandungan kimianya, seperti fenol, flavonoid, alkaloid, dan triterpenoid/steroid. ${ }^{1,2}$ Selama ini yang dikenal dari Ocimum sanctum yaitu buahnya yang merupakan campuran dalam minuman sirup. Ocimum sanctum mengandung minyak atsiri (1\%, yaitu estragol, linalool, eugenol, methyl chavicol dan sejumlah kecil cinnamate methyl, cineole, dan terpen), saponin, flavonoid (apigenin, luteolin, orientin, vicenin), tanin, dan asam-asam fenolat. ${ }^{1,2}$

Flavonoid mempunyai banyak efek yang baik terhadap kesehatan tubuh manusia. Para peneliti menemukan flavonoid yang bermanfaat sebagai antioksidan; berperan sebagai molekul messenger dalam interaksi antar sel; antiinflamasi dengan memutus efek jalur metabolisme asam arakidonat, mempengaruhi produksi prostaglandin dan pelepasan histamin, mempunyai aktivitas scavenging, antitumor dengan memutus aktivitas promoter tumor, dan antivirus diperkirakan memutus sintesis asam nukleat. ${ }^{3,4}$

Kandungan flavonoid dalam daun Ocimum sanctum telah dikembangkan penggunaannya menjadi tumbuhan obat. Devi dkk. ${ }^{5}$ menemukan orientin dan vicenin yang melindungi mencit dari pengaruh radiasi, mekanismenya didasarkan pada aktivitas antioksidan yang melindungi lipid dari oksidasi. Orientin dan vicenin, dua isolat flavonoid dari daun Ocimum scantum yang larut dalam air, menunjukkan perlindungan terhadap radiasi dan aberasi kromosom signifikan secara in vivo. ${ }^{6}$ Siddique dan $\mathrm{Afzal}^{7}$ menemukan ekstrak Ocimum sanctum dapat melawan efek genotoxic yang diinduksi oleh cyproterone acetate dalam kultur sel mamalia. Banyak lagi efek farmakologi Ocimum sanctum yang telah ditemukan, antara lain efek antiinflamasi, analgesik dan antipiretik, antidiabetika, serta antilipidemia. ${ }^{8}$ Banyak efek yang ditimbulkan berasal dari kandungan flavonoidnya, oleh karena itu kandungan flavonoid dalam Ocimum sanctum menjadi penting untuk diketahui dan dibutuhkan metode isolasi serta identifikasi flavonoid yang cepat.

Flavonoid merupakan salah satu golongan fenol alam yang terbesar. Sebenarnya, flavonoid terdapat dalam semua tumbuhan hijau sehingga pastilah ditemukan pula pada setiap telaah ekstrak tumbuhan hijau.

Dalam tumbuhan, aglikon flavonoid (yaitu flavonoid tanpa gula terikat) terdapat dalam berbagai bentuk struktur. Semuanya mengandung 15 atom karbon dalam inti dasarnya yang tersusun dalam konfigurasi C6-C3-C6, yaitu dua cincin aromatik yang dihubungkan oleh satuan tiga karbon yang dapat atau tidak dapat membentuk cincin ketiga.
Banyak metode yang dapat digunakan untuk mengisolasi dan mengidentifikasi flavonoid. Kromatografi kertas atau kromatografi lapis tipis selulosa merupakan kromatografi yang paling umum dan berguna untuk flavonoid. Kromatogram kertas atau kromatogram selulosa dikembangkan dengan bermacam pengembang yang berguna untuk menganalisis flavonoid, antara lain: ${ }^{9,10}$ 1) BAA: n-butanol-asam asetat-air $(4: 1: 5) ; 2)$ KAA: kloroform-asam asetat-air $(30: 15: 2) ; 3)$ forestal [asam asetat-air-asam klorida (30:10:3)]; 4) Asam format [asam format-air-asam klorida (5:3:2)]; 5) BEA: n-butanol-etanol-air (4:1:2,2); 6) benzen-asam asetat-air (125:72:3); 7) Asam asetat $5 \%, 15 \%$, dan $50 \%$; serta 8 ) asam klorida $1 \%$ dan lainnya. Pada identifikasi flavonoid yang pertama dijadikan acuan dengan menafsirkan warna bercak dari segi struktur flavonoid dengan penampak bercak amoniak dan sinar ultraviolet, untuk selanjutnya diidentifikasi dilanjutkan dengan mengukur absorbansinya dengan pereaksi geser dan spektrofotometer ultraviolet-sinar tampak. ${ }^{, 10}$ Dari bermacam pengembang tersebut pada tahun 2005 diteliti pengembang yang efektif untuk flavonoid Ocimum sanctum di laboratorium Kimia Medik Fakultas Kedokteran Universitas Padjadjaran. Tujuan penelitian untuk memperoleh metode yang cepat untuk mengidentifikasi kandungan flavonoid dalam Ocimum sanctum.

\section{Metode}

Bahan yang dipakai daun Ocimum sanctum dari Bandung, pereaksi (Merck(C) berupa 95\% etanol, n-butanol, asam asetat, kloroform, asam klorida dan alumunium klorida, metanol, natrium hidroksida, natrium asetat, asam borat, serta asam klorida. Alat yang digunakan kertas Whatman No. I dan No. 3, pelat TLC selulosa, soxhlet, penampak bercak ultraviolet-sinar tampak dengan panjang gelombang $254 \mathrm{~nm}$ dan $366 \mathrm{~nm}$ (DesagaCabUvis), spektrofotometer ultraviolet-sinar tampak (DU 650i Beckman). Penghitungan statistik tidak dilakukan karena pada penelitian ini yang dicari yaitu metode cepat untuk mengidentifikasi kandungan flavonoid daun Ocimum sanctum. Pencarian dan pemisahan flavonoid dilakukan dengan mengekstraksi sinambung daun Ocimum sanctum dalam 95\% etanol dan soxhlet. Ekstrak dipekatkan dengan evaporator. Flavonoid di dalam ekstrak diisolasi dengan kertas Whatman No. 1, No. 3, TLC selulosa, dan bermacam pereaksi pengelusi, kemudian flavonoid didentifikasi dengan 5\% alumunium klorida dan sinar ultraviolet pada panjang gelombang $254 \mathrm{~nm}$ dan $366 \mathrm{~nm}$. Langkah awal flavonoid dalam ekstrak diisolasi dengan $2 \%$ asam asetat, kemudian flavonoid diisolasi 
kembali dengan bermacam pereaksi pengelusi: 1) n-butanol-asam asetat-air (4:1:5); 2) kloroformasam asetat-air $(30: 15: 2) ; 3)$ forestal [asam asetatair-asam klorida (30:10:3)]; serta 4) asam asetat $5 \%, 15 \%, 35 \%$, dan 50\%. Flavonoid dalam metanol $(\mathrm{MeOH})$ diidentifikasi dengan sinar ultraviolet pada panjang gelombang 220-550 $\mathrm{nm}$ dan pereaksi geser: natrium metanolat $(\mathrm{NaOMe})$, natrium asetat (NaOAc), campuran natrium asetat dan asam borat ( $\left.\mathrm{NaOAc} / \mathrm{H}_{3} \mathrm{BO}_{3}\right)$, alumunium klorida $\left(\mathrm{AlCl}_{3}\right)$, serta campuran alumunium klorida dan asam klorida $(\mathrm{AlCl} / \mathrm{HCl})^{9,10}$

\section{Hasil}

Pertama kali flavonoid diisolasi dari ekstrak etanol pekat dengan 2\% asam asetat, diperoleh satu bercak yang memberikan warna violet gelap pada sinar ultraviolet dengan panjang gelombang
$366 \mathrm{~nm}$ dan dengan pereaksi alumunium klorida 5\% dalam metanol, dan di bawah sinar ultraviolet pada panjang gelombang $366 \mathrm{~nm}$ memberikan warna kuning. Flavonoid tersebut diisolasi sekali lagi dengan bermacam pereaksi pengelusi, dengan penampak bercak larutan $\mathrm{AlCl}_{3}$ dalam metanol dan sinar ultraviolet pada panjang gelombang $366 \mathrm{~nm}$, diperoleh: 1) n-butanol-asam asetatair (4:1:5), hasilnya satu bercak flavonoid; 2) kloroform-asam asetat-air (30:15:2), hasilnya satu bercak flavonoid; 3) Forestal [asam asetatair-asam klorida (30:10:3)], hasilnya satu bercak flavonoid, dan 4) 35\% asam asetat, hasilnya dua bercak. Kedua isolat flavonoid diberi nama FOAc-1 dan FOAc-2. Masing-masing isolat diukur absorbansinya dalam metanol pada panjang gelombang 220 sampai $550 \mathrm{~nm}$ dengan spektrometer ultraviolet. Isolat FOAc-1 memberikan puncak absorbansi pita I: $329 \mathrm{~nm}$ dan pita II: $265 \mathrm{~nm}$. Isolat FOAc-2 memberikan

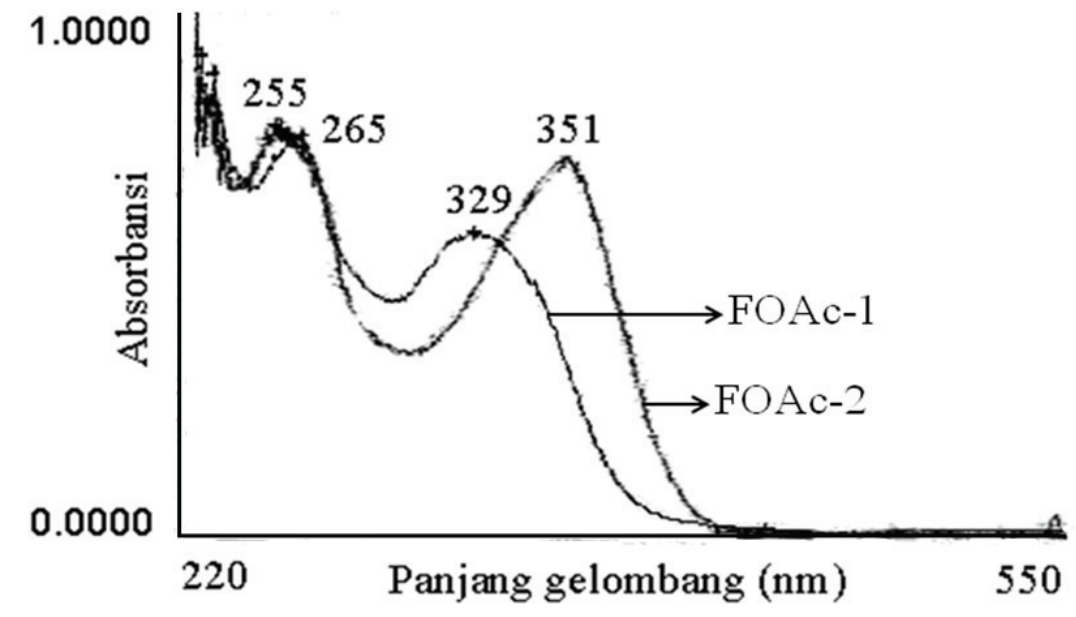

Gambar 1 Spektrum Ultraviolet Isolat FOAc-1 dan FOAc-2 dalam Metanol

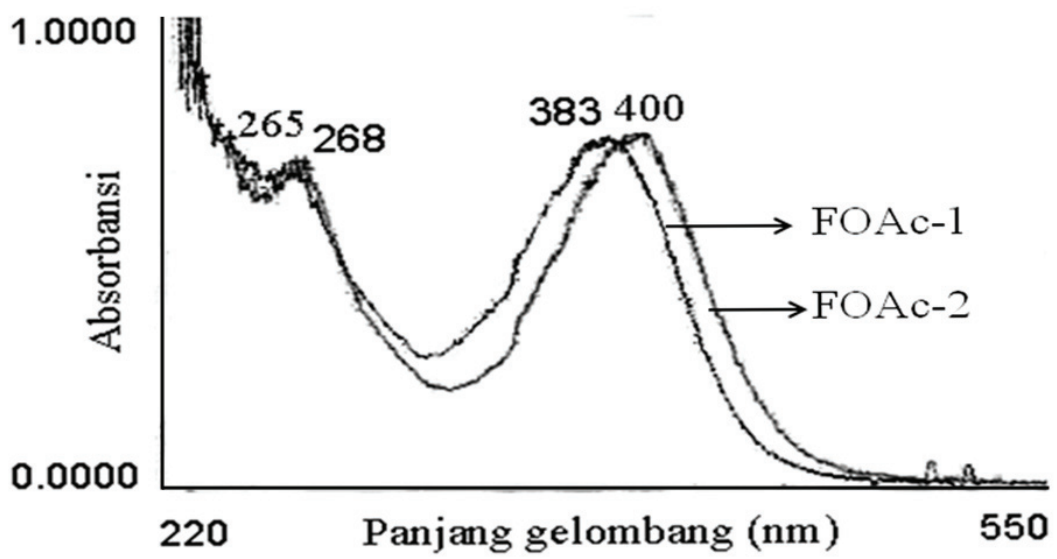

Gambar 2 Spektrum Ultraviolet Isolat FOAc-1 dan FOAc-2 dalam Metanol dengan Pereaksi Geser NaOMe 


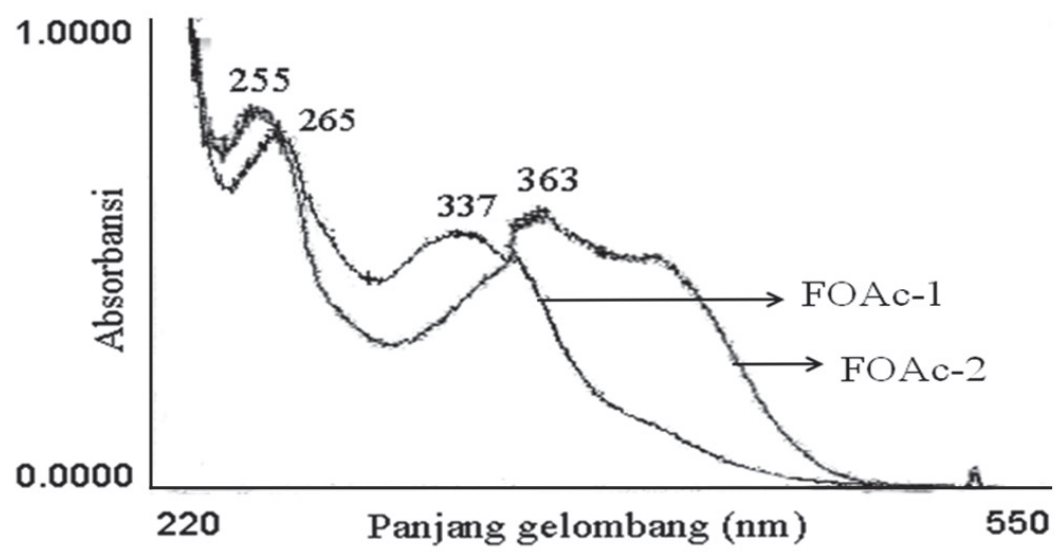

\section{Gambar 3 Spektrum Ultraviolet Isolat FOAc-1 dan FOAc-2 dalam Metanol dengan Pereaksi Geser NaOAc}

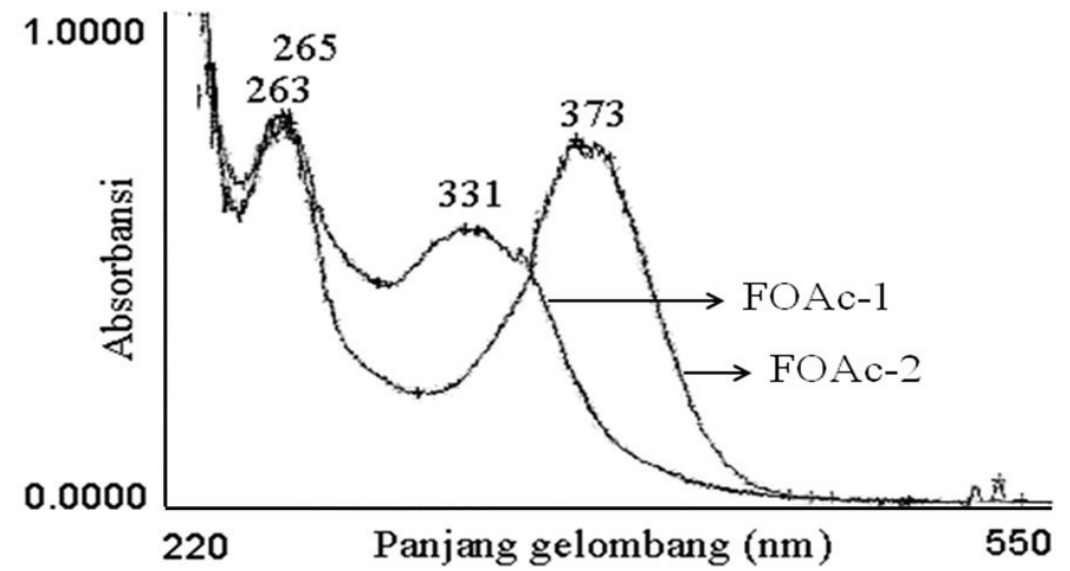

Gambar 4 Spektrum Ultraviolet Isolat FOAc-1 dan FOAc-2 dalam Metanol dengan Pereaksi Geser $\mathrm{NaOAc} / \mathrm{H}_{3} \mathrm{BO}_{3}$

puncak absorbansi pita I: $351 \mathrm{~nm}$ dan pita II: 255 $\mathrm{nm}$.

Pengukuran absorbansi ultraviolet-sinar tampak dilanjutkan dengan pengukuran geser absorbansinya dengan pereaksi geser: natrium metanolat $(\mathrm{NaOMe})$, natrium asetat $(\mathrm{NaOAc})$, campuran natrium asetat dan asam borat $\left(\mathrm{NaOAc} / \mathrm{H}_{3} \mathrm{BO}_{3}\right)$, alumunium klorida $\left(\mathrm{AlCl}_{3}\right)$, serta campuran alumunium klorida dan asam klorida $\left(\mathrm{AlCl}_{3} / \mathrm{HCl}\right)$. Data puncak absorbansi isolat FOAc-1: UV (MeOH) $\lambda_{\text {max }}$ (A) $265 \mathrm{~nm}$ $(0,74) ; 329 \mathrm{~nm}(0,57)$ (Gambar 1). UV (NaOMe) $\lambda$ (A) $268 \mathrm{~nm}(0,67) ; 383 \mathrm{~nm}(0,74)$ (Gambar 2). ${ }^{\max }$ UV (NaOAc) $\lambda_{\text {(A) }} 265 \mathrm{~nm}(0,73) ; 337 \mathrm{~nm}$ $(0,53)($ Gambar 3$)$. UV $\left(\mathrm{NaOAc} / \mathrm{H}_{3} \mathrm{BO}_{3}\right) \lambda_{\text {max }}$ (A) $265 \mathrm{~nm}(0,76) ; 331 \mathrm{~nm}(0,56)$ (Gambar 4). UV $\left(\mathrm{AlCl}_{3}\right) \lambda_{\max }$ (A) $268 \mathrm{~nm}(0,67) ; 351 \mathrm{~nm}(0,51)$ (Gambar 5). UV $\left(\mathrm{AlCl}_{3} / \mathrm{HCl}\right) \lambda_{\text {max }}$ (A) $265 \mathrm{~nm}$ $(0,69) ; 339 \mathrm{~nm}(0,53)$ (Gambar 6$)$. Data puncak absorbansi isolat FOAc-2: UV (MeOH) $\lambda_{\text {max }}$ (A)
$255 \mathrm{~nm}(0,81) ; 351 \mathrm{~nm}(0,77)$ (Gambar 1). UV (NaOMe) $\lambda_{\text {max }}$ (A) $265 \mathrm{~nm}(0,69) ; 400 \mathrm{~nm}(0,75)$ (Gambar 2). UV (NaOAc) $\lambda_{\text {max }}$ (A) $255 \mathrm{~nm}(0,84)$; $363 \mathrm{~nm}(0,61)$ (Gambar 3). UV $\left(\mathrm{NaOAc} / \mathrm{H}_{3} \mathrm{BO}_{3}\right)$ $\lambda_{\text {max }}$ (A) $263 \mathrm{~nm}(0,76) ; 373 \mathrm{~nm}(0,69)$ (Gambar 4). UV $\left(\mathrm{AlCl}_{3}\right) \lambda_{\max }$ (A) $270 \mathrm{~nm}(0,78) ; 405 \mathrm{~nm}$ $(0,82)(\mathrm{Gambar} 5)$. UV $\left(\mathrm{AlCl}_{3} / \mathrm{HCl}\right) \lambda_{\text {max }}$ (A) $262 \mathrm{~nm}(0,73) ; 383 \mathrm{~nm}(0,78)$ (Gambar 6).

\section{Pembahasan}

Dari hasil isolasi dengan asam asetat 2\% yang dilanjutkan dengan 4 macam pengembang, dari 3 macam pengembang 1) n-butanol-asam asetat-air (4:1:5), 2) Kloroform-asam asetatair (30:15:2), dan 3) Forestal [asam asetat-airasam klorida (30:10:3)], diperoleh satu bercak flavonoid. Pengembang ke-4, asam asetat 35\% diperoleh dua bercak flavonoid yang disebut 


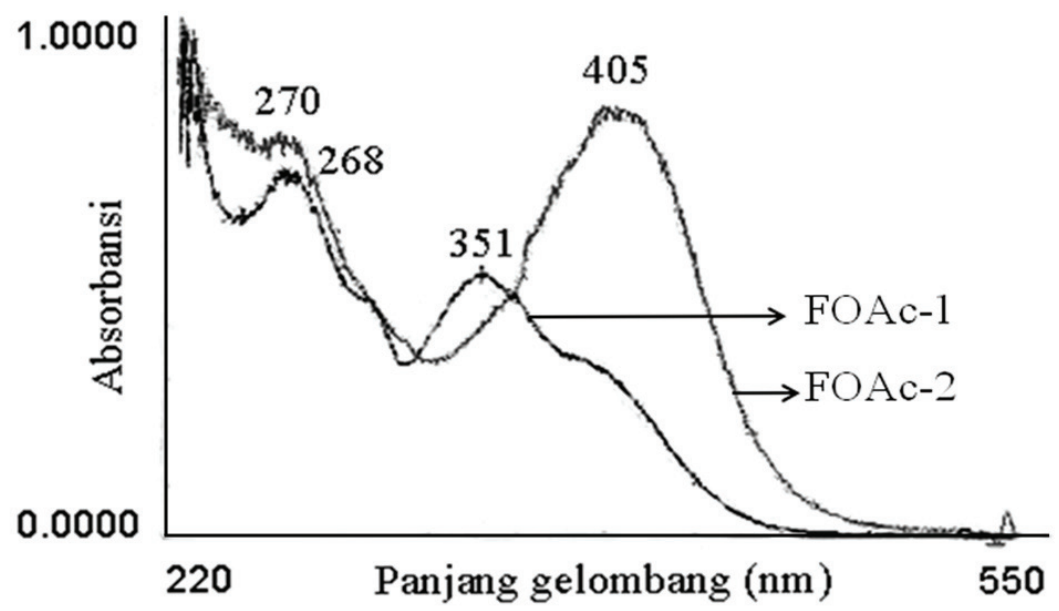

\section{Gambar 5 Spektrum Ultraviolet Isolat FOAc-1 dan FOAc-2 dalam Metanol dengan Pereaksi Geser $\mathrm{AICI}_{3}$}

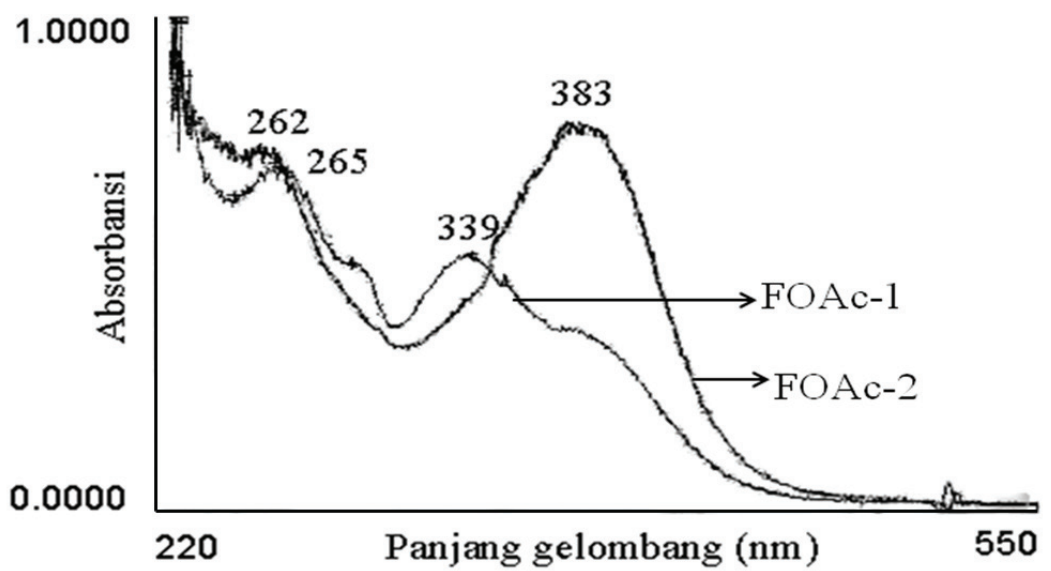

\section{Gambar 6 Spektrum Ultraviolet Isolat FOAc-1 dan FOAc-2 dalam Metanol dengan Pereaksi Geser AlCl3/Hcl}

FOAc-1 dan FOAc-2.

Identifikasi dua bercak flavonoid hasil pengembangan dengan asam asetat $35 \%$, dengan sinar ultraviolet pada panjang gelombang 220 $550 \mathrm{~nm}$ dan pereaksi geser flavonoid, diperoleh data puncak absorbansi FOAc-1, pita I: $329 \mathrm{~nm}$, pita II: $265 \mathrm{~nm}$, puncak absorbansi FOAc-2, pita I: $351 \mathrm{~nm}$, pita II: $255 \mathrm{~nm}$. Pola puncak absorbansi kedua isolat diperkirakan mengkuti pola puncak absorbansi flavonoid, yaitu sebagai berikut, pita I: 310-350 adalah absorbansi cincin sinamoil, pita II: 250-280 adalah absorbansi cincin benzoil. Dari perubahan warna violet gelap pada sinar ultraviolet dengan panjang gelombang 366 $\mathrm{nm}$ dan dengan pereaksi alumunium klorida $5 \%$ dalam metanol, dan pola puncak absorbansinya, kedua isolat diperkirakan golongan flavon.

Data spektrum ultraviolet isolat FOAc-1: 1) Dalam metanol (Gambar 1) pita I: $329 \mathrm{~nm}$ dan pita II: 265 nm. 2) Dalam natrium metanolat (Gambar 2) pita I: $383 \mathrm{~nm}$ dan pita II: $268 \mathrm{~nm}$, terjadi geseran batokromik $54 \mathrm{~nm}$ pada pita I, dan absorbansi stabil, diduga ada gugus 4'-OH bebas. 3) Dalam natrium asetat (Gambar 3) pita I: $337 \mathrm{~nm}$ dan pita II: $265 \mathrm{~nm}$, tidak terjadi geseran batokromik pada pita II, diduga tidak ada gugus 7-OH bebas. 4) Dalam natrium asetatasam borat (Gambar 4) pita I: $331 \mathrm{~nm}$ dan pita II: $265 \mathrm{~nm}$, terjadi geseran batokromik $4 \mathrm{~nm}$ pada pita I, diduga tidak ada $o$-diOH pada cincin-B. 5) Dengan alumunium klorida (Gambar 5) pita I: $351 \mathrm{~nm}$ dan pita II: $268 \mathrm{~nm}$, terjadi geseran batokromik $22 \mathrm{~nm}$ pada pita I, diduga ada gugus 5-OH bebas. 6) Dalam alumunium klorida-asam hidroklorida (Gambar 6) pita I: $339 \mathrm{~nm}$ dan pita II: $265 \mathrm{~nm}$, terjadi geseran batokromik $10 \mathrm{~nm}$ pada pita I, diduga tidak ada $o$-diOH pada cincin-B.

Data spektrum ultraviolet isolat FOAc-2: 1) 
dalam metanol (Gambar 1) pita I: $351 \mathrm{~nm}$ dan pita II: $255 \mathrm{~nm}, 2$ ) dalam natrium metanolat (Gambar 2) pita I: $400 \mathrm{~nm}$ and pita II: $265 \mathrm{~nm}$, terjadi geseran batokromik $49 \mathrm{~nm}$ pada pita I dan absorbansi stabil, diduga ada gugus 4'$\mathrm{OH}$ bebas, 3) dalam natrium asetat (Gambar 3) pita I: $363 \mathrm{~nm}$ dan pita II: $255 \mathrm{~nm}$, tidak terjadi geseran batokromik pada pita II, diduga tidak ada 7-OH bebas, 4) dalam natrium asetat- asam borat (Gambar 4) pita I: $373 \mathrm{~nm}$ dan pita II: 263 $\mathrm{nm}$, terjadi geseran batokromik $22 \mathrm{~nm}$ pada pita I, diduga ada $o$-diOH pada cincin-B, 5) dalam alumunium klorida (Gambar 5) pita I: $405 \mathrm{~nm}$ dan pita II: $270 \mathrm{~nm}$, terjadi geseran batokromik $54 \mathrm{~nm}$ pada pita I, diduga ada gugus $5-\mathrm{OH}$ bebas, 6) dalam alumunium klorida-asam hidroklorida (Gambar 6) pita I: $383 \mathrm{~nm}$ dan pita II: $262 \mathrm{~nm}$, terjadi geseran batokromik $32 \mathrm{~nm}$ pada pita I, diduga ada gugus $o$-diOH pada cincin-B.

Dari uraian di atas, FOAc-1 flavon dengan $\mathrm{Rf}=0,69$; pita I: $329 \mathrm{~nm}$ dan pita II: $265 \mathrm{~nm}$; terdapatnya gugus 4'-OH bebas dan gugus $5-\mathrm{OH}$ bebas. FOAc-2 flavon dengan $\mathrm{Rf}=0,57$; pita I: $351 \mathrm{~nm}$ dan pita II: $255 \mathrm{~nm}$; terdapatnya gugus 4 '-OH bebas, gugus $5-\mathrm{OH}$ bebas dan $o$-diOH pada cincin-B.

Dari perolehan flavonoid seperti tersebut di atas, untuk tiga macam pengembang yang hanya memberikan satu bercak flavonoid, masih diperlukan pengembangan lebih lanjut supaya memperoleh hasil pengembangan yang lebih baik. Untuk pengembang asam asetat 35\% diperoleh hasil yang lebih baik, berdasarkan analisis karakteristik spektrum ultravioletnya kedua bercak merupakan flavon.

Dengan demikian, dapat disimpulkan metode identifikasi flavonoid dari Ocimum sanctum dengan asam asetat $2 \%$ dan $35 \%$ berturut-turut lebih cepat daripada ketiga pengembang lainnya.

\section{Daftar Pustaka}

1. Hutapea JR, Djumidi, Sutjipto, Sugiarso S, Soerahso, Sihotang, dkk. Dalam: Darwanto, penyunting. Inventaris tanaman obat Indonesia, Ocimum sanctum L. (Selasih). Volume ke-1. Jilid ke-2. Jakarta: Departemen Kesehatan; 2001. hlm. 247-8.
2. Dalimartha S. Dalam: Dahlianti R, penyunting. Atlas tumbuhan obat Indonesia. Jilid ke-5. Jakarta: Pustaka Bunda; 2008. hlm. 156-8.

3. Annadana S. Medicinal Herb Tulsi (Ocimum sanctum); Medicinal plants [Online serial] 15-06-2006. [diunduh 29 Agustus 2010]. Tersedia dari: http://www. AgricultureInformation_com.mht.

4. Ocimum Sanctum; Section tanaman obat Galeri tanaman obat [diunduh 12 Desember 2008]. Tersedia dari: http://www.Tanamanobat.com.

5. Devi UP, Ganasoundari A, Vrinda B, Srinivasan KK, Unnikrishnan MK. Radiation protection by the ocimum flavonoids orientin and vicenin: mechanisms of action. Radiat Res [Online serial] 2000 Oct. [diunduh 29 Agustus 2010]. Tersedia dari: http://www. PubMed.gov.

6. Vrinda B, Uma DP. Radiation protection of human lymphocyte chromosomes in vitro by orientin and vicenin. Mutat Res [Online serial] 2001 Nov 15;498(1-2):39-46. [diunduh 29 November 2010]. Tersedia dari: http://www.PubMed.gov.

7. Siddique YH, Afzal M. Ocimum sanctum L. extract can against genotoxic effect that was induced by cyproterone acetate in culture mammalian cells. Internet $\mathrm{J}$ Pharmacol [Online serial] 2008;6(1). [diunduh 10 Agustus 2010]. Tersedia dari: ISPUB.com.

8. Mondal S, Mirdha BR, Mahapatra SC. The science behind sacredness of Tulsi (Ocimum sanctum Linn.). Indian J Physiol Pharmacol. 2009;53(4):291-306.

9. [Dhianawaty DD, Padmawinata K, Soediro I, Soemardji AA. Isolasi, karakterisasi dan uji aktivitas antikalkuli luteolin 7-O-glukosida dari daun Sonchus arvensis L. pada tikus dengan metode matrix-asam glikolat. Bionatura. 2003;5(3):196-202.

10. Dhianawaty DD, Padmawinata K, Soediro I, Soemardji AA. Isolasi, karakterisasi dan uji aktivitas antikalkuli apigenin 7-O-glukosida dari daun Sonchus arvensis L. pada tikus dengan metode matrix-asam glikolat. Jurnal Bahan Alam Indonesia. 2004;3(1):162-4. 